\title{
The Infrared Spectra of Customized Magnesium/Teflon/Viton (MTV) Decoy Flares to Thermal Signature of Jet Engine
}

\author{
$\left\{\text { Amir Elsaidy }{ }^{*} \text {, Mohamed Kassem, Hesham Tantawy }{ }^{\dagger} \text { and Sherif Elbasuney }\right\}^{\S}$
}

\begin{abstract}
Decoy flares are customized materials, which are capable of yielding thermal signature to interfere with IR guided missile seekers. In this study, different decoy flares compositions based on Magnesium/Teflon/Viton (MTV) (with fuel percentage ranging from 40:70 wt \%) were developed by granulation and subsequent pressing. The spectral performance of developed decoy flare formulations was measured to thermal signature of jet engine nozzle using (FT-MIR 2-6) spectrophotometer. The jet engine thermal signature was characterized with two characteristic peaks over $\alpha$ band $(2-3 \mu \mathrm{m})$ and $\beta$ band $(3-5 \mu \mathrm{m})$; this signature was correlated to black body emission by the nozzle at $690{ }^{\circ} \mathrm{C}$. Absorption of the IR emission by air could attenuate the signal over the band 3-4 $\mu \mathrm{m}$ due to $\mathrm{CO}_{2}$ and $\mathrm{H}_{2} \mathrm{O}$ IR absorption. The characteristic intensity ratio of jet engine nozzle $(\alpha / \beta)=0.26$. The developed decoy flares offered similar thermal signature but with higher intensity due to the formation carbon soot and $\mathrm{MgF}_{2}$ as black body and active IR emitter respectively. Quantification of these emitting species in the combustion flame was performed using the ICT thermodynamic code. MTV decoy flare with $65 \mathrm{wt} \% \mathrm{Mg}$ offered an increase in the intensity of $\alpha$ band and $\beta$ by 21 and 4 times respectively. This customized formulation offered the formation of $\mathrm{MgF}_{2}$ (molecular emitter) and $\mathrm{C}$ soot (grey emitter) at 42.4 , and $8.8 \mathrm{wt} \%$ respectively. It is also offered $48 \mathrm{wt} \% \mathrm{Mg}$ fuel which would be oxidized in the flame and add much more heat with the formation of $\mathrm{MgO}$ (grey body). The characteristic intensity ratio $\Theta$ was found to be 0.96 . This is manuscript would open the route for the development of customized decoy flares with tailored spectral performance.
\end{abstract}

Keywords: Decoy flares, MTV, Infrared, spectroscopy, thermal signature.

\section{Introduction:}

Infrared (IR) guided missile is one of the major threats to military aircrafts [1]. IR missile seekers detect the combined radiation and identify the aircraft as a potential target $[2,3]$. IR signature of an aircraft is generated by several components of the metal skin, jet engine, and plume. The aircraft fuselage emit between 8-10 microns, due to sun radiation or air friction. Radiation between 3-5 microns is emitted from hot exhausts $\left(\mathrm{H}_{2} \mathrm{O}, \mathrm{CO}, \mathrm{CO}_{2}\right)$, whereas hot jet engines (main IR radiation source) emit in the range of 2-2.5 microns (Figure 1) [4].

Heat-seeking missiles normally search for radiation emitted from the aircraft over $\alpha(2-3 \mu \mathrm{m})$ and $\beta(4-5 \mu \mathrm{m})$ bands [6]. Countermeasures that can be used to protect against a thermal detector include [1,7]: 


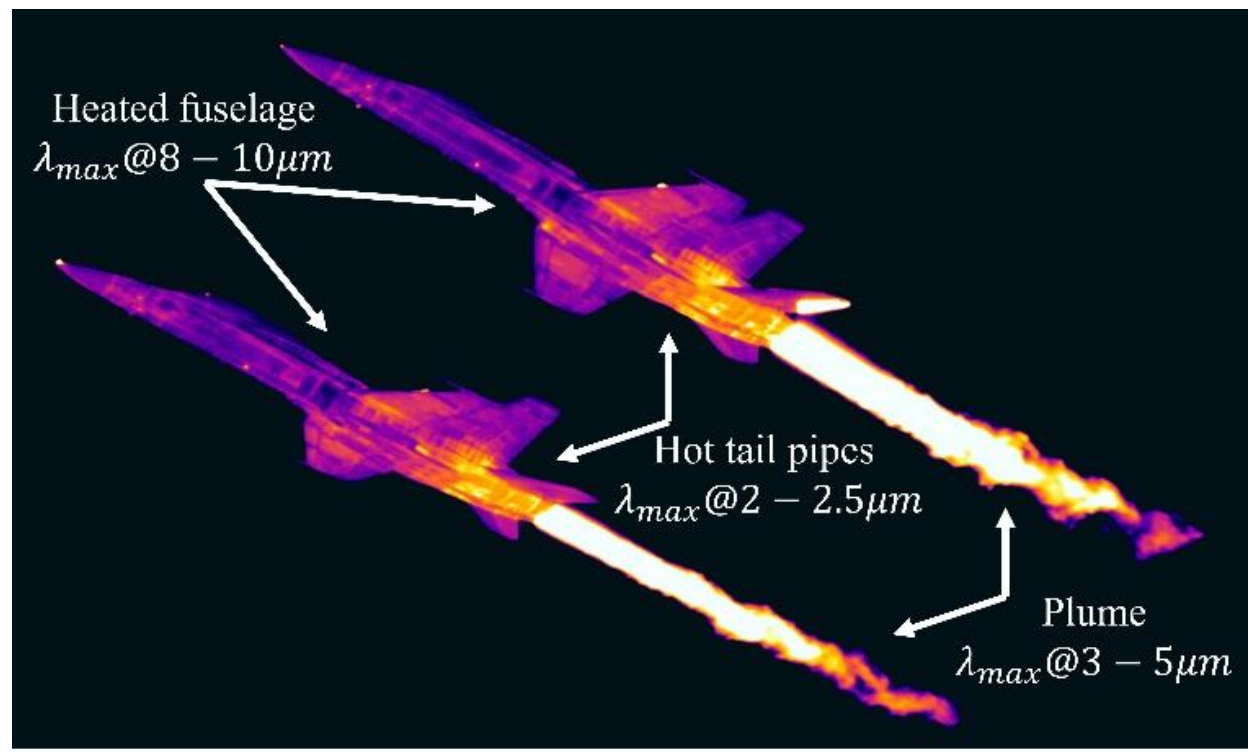

Fig.1. Main infrared radiation sources of an aircraft [5]

* A pyrotechnic flare that emits high-intensity output of infrared radiation.

* A pyrotechnic smoke, where the smoke particles absorb and scatter radiation emitted by the warm target.

* Multiple decoys that are emitting infrared radiation of the type and energy output that mimic what the detector is specifically looking for.

Decoy flare is an aerial infrared countermeasure to counter the infrared homing (passive missile guidance system) [8-12]. Such flares are based on very hot burning metals with burning temperatures equal or hotter than an engine exhaust. Decoy flare compositions should burn with similar radiation as the aircraft but with higher intensity [13]. For tactical reasons the aircraft can ignite decoy flares to seek out IR missiles from the aircraft to the burning flare.

\subsection{IR Decoy Flares:}

The first attempt to seek out IR missiles is classical Illuminating decoy flares based on $\mathrm{Mg} / \mathrm{NaNO} 3$ and laminac as a binder [14]. The main combustion product of such flares is $\mathrm{MgO}$; the overall emittance of $\mathrm{MgO}$ is low compared to black bodies [15]. As carbon black behaves like a black body. Consequently, pyrotechnic systems generating large amounts of heat and carbon black were developed. Decoy flare compositions based on magnesium and fluorinated polymers fulfilled these requirements [16]. Standard decoy flares consist of Magnesium (fuel), Teflon (oxidizer), and Viton (binder); they are commonly known as MTV flares. MTV flares offered good ignition behavior and high heat of reaction; this enabled the use of MTV as alternative materials to classical igniter compositions [17-19].

\subsubsection{Magnesium / Teflon / Viton (MTV)}

The initial combustion stage of MTV system can be described according to equation (1).

$$
\mathrm{m} \mathrm{Mg}+-(\mathrm{C} 2 \mathrm{~F} 4)-\rightarrow \quad 2 \mathrm{MgF} 2+\mathrm{m}-2 \mathrm{Mg}+2 \mathrm{C}+\mathrm{h} \mu
$$

MTV combustion reaction requires to take in account the oxygen provided by the atmosphere. This causes an afterburning of vaporized magnesium and carbonaceous particles. The heat of formation of $\mathrm{MgF} 2$ heats up carbon black to temperatures around $2200 \mathrm{~K}$ yielding high radiant emittance values as a black body emission. Magnesium rich compositions yielding extra energy by atmospheric oxidation of vaporized magnesium in the gas phase $\left(\mathrm{Tv}=1100 \mathrm{C}^{0}\right)$ increasing the reaction temperature to $3100 \mathrm{~K}$, in addition carbon black oxidized to carbon dioxide CO2providing additional energy and increasing radiant emittance in the (3-5 $\mu \mathrm{m})$. Thus overall reaction can be described according to equation 2 . 


$$
\mathrm{m} \mathrm{Mg}+-(\mathrm{C} 2 \mathrm{~F} 4)-+1 \mathrm{O} 2 \rightarrow 2 \mathrm{MgF} 2+\mathrm{m}-2 \mathrm{MgO}+2 \mathrm{CO} 2+\mathrm{h} \mu
$$

The products released by these reactions dominate the spectral characteristic of MTV flares.

\subsection{Radiometric Principles}

For IR emitting compositions, it is important to compare the signature of aircrafts and decoy flares. The intensity ratio parameter $(\theta)$ is useful discussing the intensity of (new) formulations. Term $\theta$ gives the ratio of the intensity in the $\alpha$ band $(2-3 \mu \mathrm{m})$ to the intensity of the $\beta$ band (3$5 \mu \mathrm{m})$ (Equation 3).

$$
\theta=\mathrm{I}_{\alpha} / \mathrm{I}_{\beta}
$$

Hot components emit in the $\alpha$ band and the exhaust emit in the $\beta$ band. The $\theta$ values of an aircraft are in the range of 0.7 [31]. So new decoy flares should have values similar to that of the aircraft to countermeasure infrared missiles attacks. Figure 2 demonstrates the radiant intensity of an aircraft compared to commonly used MTV flares.

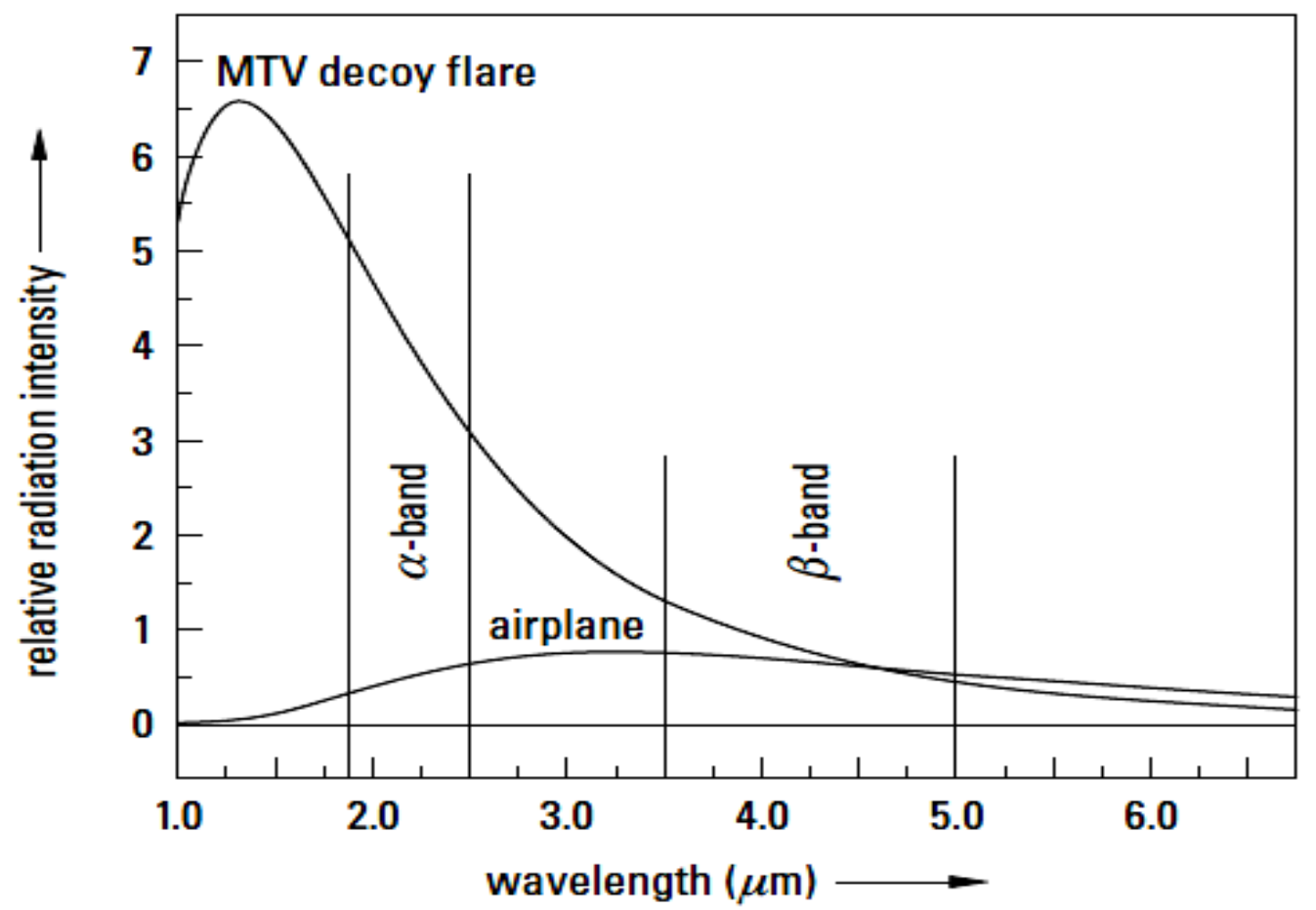

Fig. 2. Comparison of relative magnitude of MTV and target [1]

The principle of decoy flares emission is based on black body radiation, due to high burning temperatures and combustion of condensed products. According to Plank's law, the radiant emittance of radiating body can be described as Equation 4:

$$
\mathrm{W}_{\lambda}=\frac{2 \pi \mathrm{hc}^{2}}{\lambda^{5}} \frac{1}{\mathrm{e}^{\mathrm{hc}}}
$$

where, $\mathrm{W}_{\lambda}$ is the spectral radiant emittance in $\mathrm{W} \mathrm{cm}^{-2} \mu \mathrm{m}^{-1}, \lambda=$ wavelength in $\mu \mathrm{m}, \mathrm{h}$ is the Plank's constant $6.626 \times 10^{-34} \mathrm{~W} \mathrm{~S}^{-2}, \mathrm{~T}=$ absolute temperature in Kelvin, c = velocity of light $2.998 \times 10^{10} \mathrm{~cm} / \mathrm{s}$, and $\mathrm{k}$ is Boltzmann constant $1.381 \times 10-{ }^{23} \mathrm{~W} \mathrm{~s} \mathrm{~K}^{-1}$.

The emission maximum ( $\left.\lambda_{\max }\right)$ shifts to shorter wavelengths (Wien's displacement law) as the temperature of the radiator rises (Equation 5):

$$
\lambda_{\max } T=2898 \mu m . K
$$


As Plank's law is valid for an ideal black body emitter, true decoys are rather grey bodies. To describe the deviation from the ideal case to real behavior, the emissivity $\varepsilon$ is introduced. The emissivity gives the ratio of the radiant emittance $W^{\prime}$ of a real radiator to the radiant emittance $\mathrm{W}$ of a black body of the same temperature (Equation 6).

$$
\varepsilon=\frac{W \prime}{W}
$$

$\varepsilon$ can range from unity (black body) to zero for non-radiation sources. Figure 3 demonstrates the radiant emittance $\mathrm{W}$ for grey body to black body at $1100 \mathrm{~K}[1,28]$.

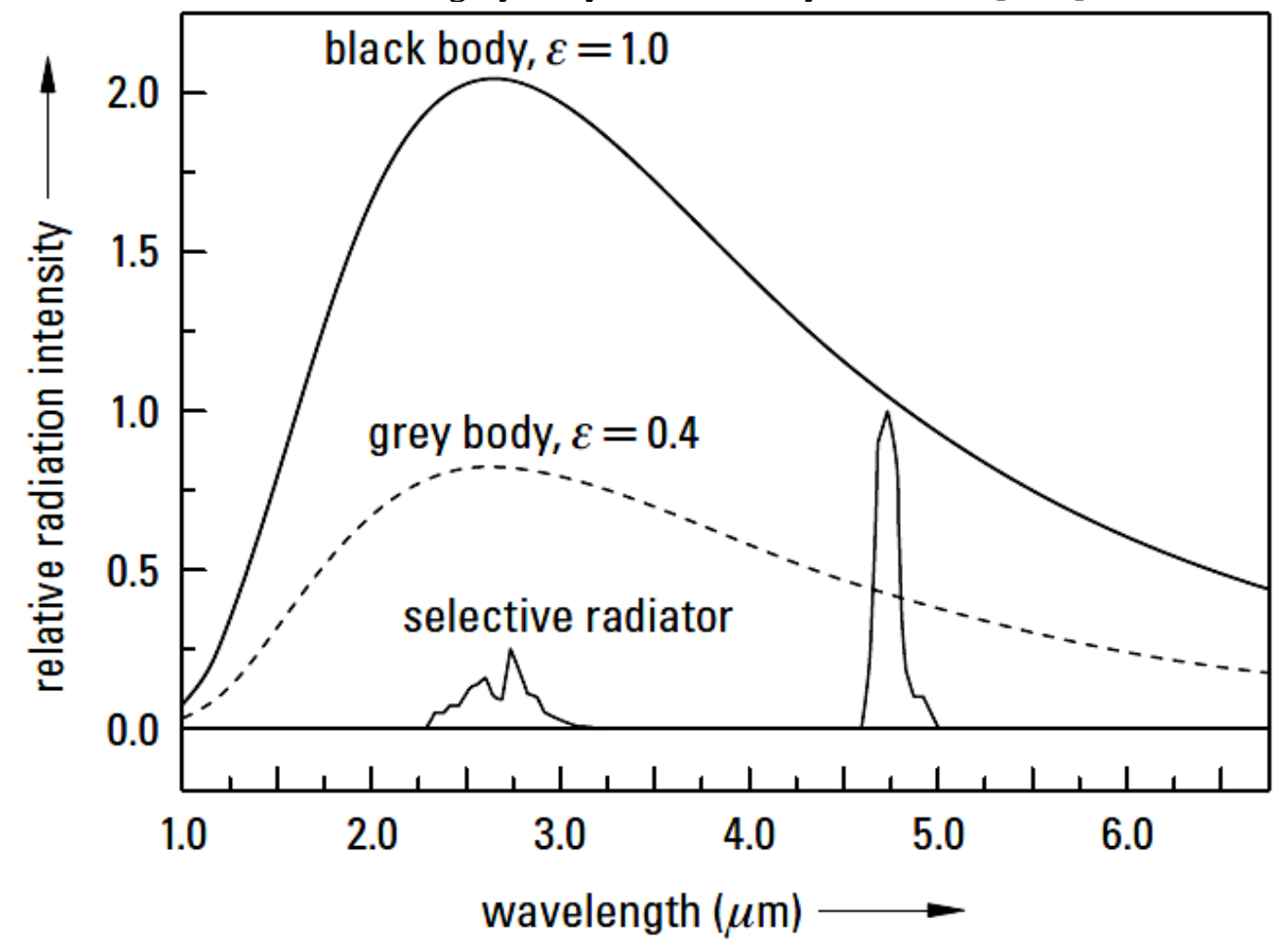

Fig. 3. Radiant emittance $\mathrm{W}$ for $1100 \mathrm{~K}$ for black body, grey body, and a selective radiator

A good grey body emitter is soot $(\varepsilon=0.95)$ which is formed during combustion of MTV flares. The main parameters of decoy flares based on black body attitudes are high $\varepsilon$ values, high combustion temperatures and $\theta$ values between $0.5-0.8$. Recent decoy flares have $\theta$ values of 1.3-1.4 [31]. $\mathrm{Mg}$ rich compositions yield some extra energy by oxidation of vaporized magnesium in the gas phase $(\mathrm{T}=3100 \mathrm{~K})$. In addition, carbon released by fluorine elimination from the carbon backbone is oxidized yielding carbon dioxide $\left(\mathrm{CO}_{2}\right)$ providing additional radiant energy. So that MTV spectral distribution displays the peak maximum at $2.0 \mu \mathrm{m}$ and strong emission bands at $4.3 \mu \mathrm{m}$ due to $\mathrm{CO}_{2}$ emission of approximately two fold the intensity of the gray body level [1]. There are several approaches to alter the radiant intensity of MTV flares. Altering the radiant intensity of MTV flares requires physical and chemical means to be applied [20-27].

In this study, the thermal signature of real jet engine was measured using (FT-MIR 2-6) spectrophotometer. Jet engine thermal signature was characterized with two characteristic peaks over $\alpha$ and $\beta$ bands; this thermal signature was mainly correlated to black body emission by the hot nozzle at $690{ }^{\circ} \mathrm{C}$. Intensity ratio $(\Theta)$ is one of the main factors to be quantified; the characteristic intensity ratio for jet engine was found to be 0.26 . Absorption of the IR emission by air $\left(\mathrm{CO}_{2}\right.$ and $\left.\mathrm{H}_{2} \mathrm{O}\right)$ could attenuate the signal over the band 3-4 $\mu \mathrm{m}$. MTV decoy flares with different fuel percentage were developed and pressed in the desired dimension; their spectral performance was measured and analyzed to jet engine thermal signature. There was an increase 
in intensity of $\alpha$ and $\beta$ bands with the increase in $\mathrm{Mg}$ content. Decoy flare formulation based on $65 \mathrm{wt} \% \mathrm{Mg}$ as fuel, $30 \mathrm{wt} \%$ Teflon as oxidizer and $5 \mathrm{wt} \%$ Viton as a binder offered an increase in the intensity of $\alpha$ band and $\beta$ by 21 and 4 times respectively. Quantification of combustion temperature and the main active emitting species (c soot (gery emitter), $\mathrm{MgF}_{2}$ (molecular emitter), and $\mathrm{Mg}$ (heat source)) in the combustion flame was conducted using chemical equilibrium computer program named ICT Thermodynamic Code (Institute of Chemical Technology in Germany, virgin 2008). Customized MTV formulation offered the highest percentage of $\mathrm{MgF}_{2}(\mathrm{~L})(42 \mathrm{wt} \%), \mathrm{Mg}(48 \mathrm{wt} \%)$ and carbon black of $(8.8 \mathrm{wt} \%)$ in the combustion flame. The relative intensity value for this formulation was found to be 0.96 ; this value was found to be in good accordance with literature. This manuscript could open the route for the development of customized decoy flares with tailored spectral performance.

\section{Experimental Work}

\subsection{Thermal Signature of Jet Engine Nozzle}

Thermal signature of jet engine nozzle (jet cat P200 SX turbine with heavy-duty starter) was measured using (FT-MIR 2-6) spectrophotometer. The thermal signature of jet engine was characterized with two characteristic peaks over $\alpha$ band $(2-3 \mu \mathrm{m})$ and $\beta$ band $(3-5 \mu \mathrm{m})$; the jet engine thermal signature was correlated to black body emission by the nozzle at $690{ }^{\circ} \mathrm{C}$. Absorption of the IR emission by air $\left(\mathrm{CO}_{2}\right.$ and $\left.\mathrm{H}_{2} \mathrm{O}\right)$ could attenuate the signal over the region 3-4 $\mu \mathrm{m}$ due to $\mathrm{CO}_{2}$ and $\mathrm{H}_{2} \mathrm{O}$ IR absorption [30]. This jet engine has $\Theta$ value of approximately 0.3. Figure 4 demonstrates the thermal signature of jet engine nozzle.

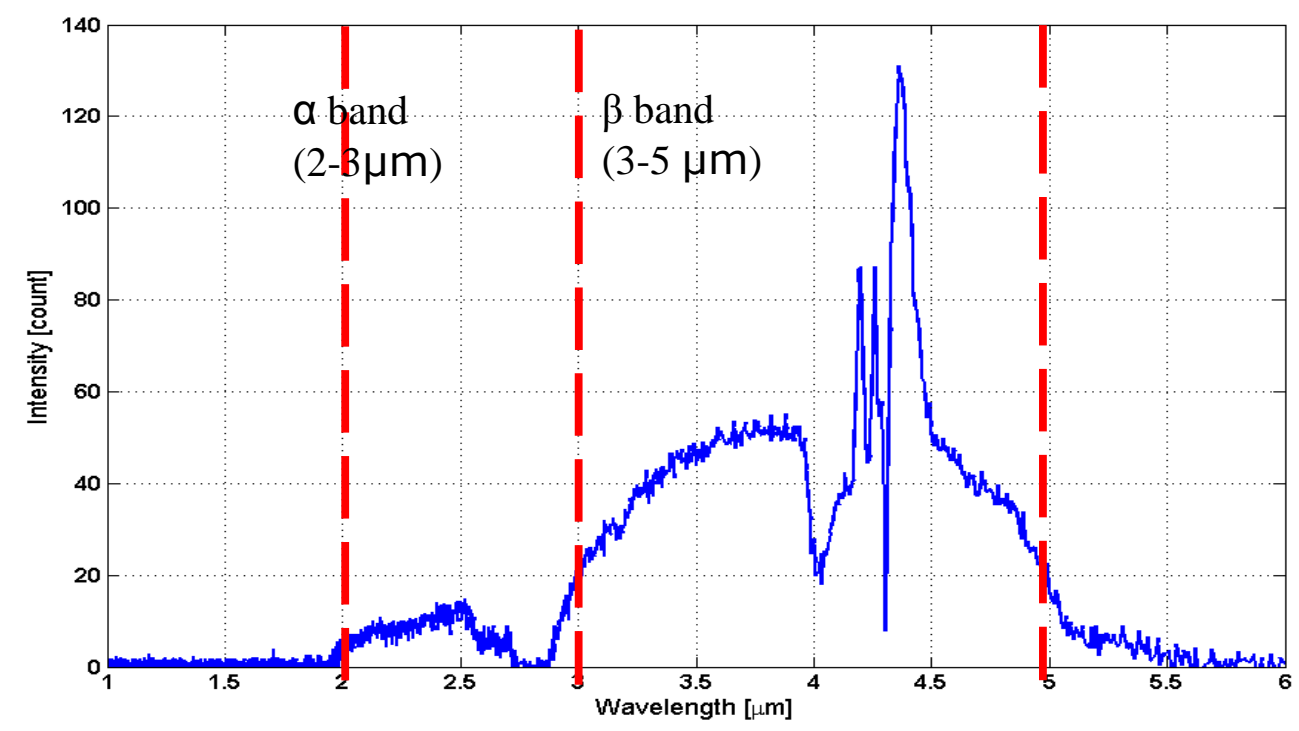

Fig. 4. Imprint spectrum of jet engine nozzle

\subsection{Decoy flares formulation:}

\subsubsection{Chemicals and materials:}

The main constituents for decoy flare manufacture include oxidizer, metal fuel, and binder. One constituent can have a dual function. Teflon can act as a binder and an oxidizer; Viton A can act as plasticizer and binder. Table 1 tabulates a list of chemicals used in this study. 
Table 1. The function and structure of different used chemicals

\begin{tabular}{c|c|c|c|c}
\hline \hline Chemicals & Function & Structure & Grade & Supplier \\
\hline \hline Teflon & $\begin{array}{c}\text { Oxidizer } \\
\& \text { binder }\end{array}$ & {$\left[-\mathrm{CF}_{2}-\mathrm{CF}_{2}\right]_{\mathrm{n}}$} & $\begin{array}{c}\text { Analytical } \\
\text { grade }\end{array}$ & $\begin{array}{c}\text { Alpha } \\
\text { chemika }\end{array}$ \\
\hline Magnesium & Fuel & $\mathrm{Mg}$ & $98 \%$,ribbon & $\begin{array}{c}\text { Alpha } \\
\text { chemika }\end{array}$ \\
\hline Viton A & plasticizer & {$\left[\mathrm{CH}_{2}-\mathrm{CF}_{2}-\mathrm{CF}_{2}-\mathrm{CF}_{3}\right]$} & $\begin{array}{c}\text { Analytical } \\
\text { grade }\end{array}$ & $\begin{array}{c}\text { Alpha } \\
\text { chemika }\end{array}$ \\
\hline \hline
\end{tabular}

A systematic study, to develop MTV flares with enhanced spectral performance that mimic aircraft signature, was conducted. This study includes the following main steps:

Fuel percentage range (40:70) wt \%.

Oxidizer percentage range $(25: 55) \mathrm{wt} \%$.

Binder percentage $5 \mathrm{wt} \%$.

Table 2 summarizes the chemical composition of different investigated MTV formulations.

Table 2 . Chemical composition of developed decoy flares

\begin{tabular}{c||c|c|c}
\hline \hline Formulation & $\begin{array}{c}\mathrm{Mg} \\
\mathrm{wt} \%\end{array}$ & $\begin{array}{c}\text { Teflon } \\
\text { wt } \%\end{array}$ & $\begin{array}{c}\text { Viton A } \\
\text { wt \% }\end{array}$ \\
\hline \hline $\mathrm{F}_{1}$ & 40 & 55 & 5 \\
\hline $\mathrm{F}_{2}$ & 45 & 50 & 5 \\
\hline $\mathrm{F}_{3}$ & 50 & 45 & 5 \\
\hline $\mathrm{F}_{4}$ & 55 & 40 & 5 \\
\hline $\mathrm{F}_{5}$ & 60 & 35 & 5 \\
\hline $\mathrm{F}_{6}$ & 65 & 30 & 5 \\
\hline $\mathrm{F}_{7}$ & 70 & 25 & 5 \\
\hline \hline
\end{tabular}

Decoy flares development should emphasize mixing of different ingredients to the molecular level, good homogenization, and accepted mechanical properties. In this study, the decoy flares manufacture included five main steps as follow:

1. Sieving of solid particles to fine powder less than $300 \mu \mathrm{m}$ particle size distribution of $\operatorname{Mg} 80 \%(250-300 \mu \mathrm{m}) \& 20 \%(<250 \mu \mathrm{m}) \&$ Fine white powder for Teflon with grain size $10 \%<2 \mu \mathrm{m}, 90 \%<20 \mu \mathrm{m}$.

2. Intimate mixing of oxidizer, fuel, and binder.

3. Granulation to retain the homogeneity of the composition otherwise light and dense materials might segregate during transportation, processing, and storage.

4. Filling, by Loading $25 \mathrm{gm}$ of the composition into metal cylinder of $2.5 \mathrm{~cm}$ diameter.

5. The final product was achieved by applying a pressure of $200 \mathrm{~atm}$.

All investigated formulations were prepared with the same methodology, to avoid any variability which would affect the performance. Figure 5 shows the main steps for manufacture of flares. 


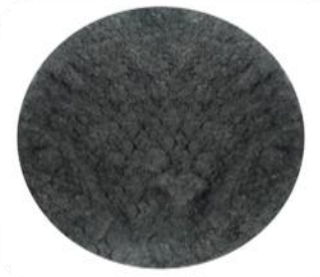

Ingredient mixing with binder

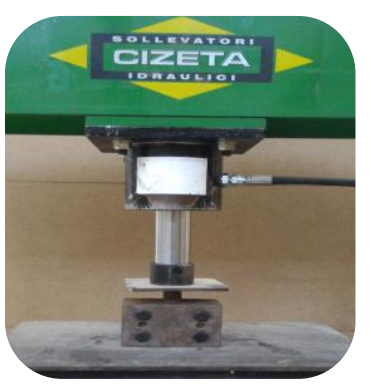

Pressing

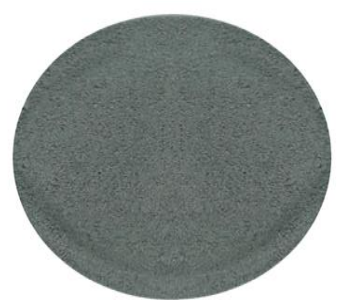

Granulation

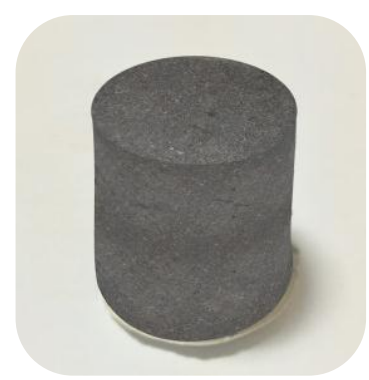

Final flare

grain

Fig. 5. The main manufacture steps of decoy flares

The employed equipment in decoy flare preparation and spectral testing are scheduled in Table 3.

Table 3. The employed equipment's in decoy flare preparation

\begin{tabular}{c|c}
\hline \hline Equipment & Function \\
\hline \hline 10000 psi electronic press & $\begin{array}{c}\text { Pressing the mixture forming a coherent } \\
\text { homogenized final product for transportation, } \\
\text { handling, and testing. }\end{array}$ \\
\hline Die & $\begin{array}{c}\text { A steal body with the required dimensions for } \\
\text { flare pressing. }\end{array}$ \\
& $\begin{array}{c}\text { For wavelength and intensity measurements. } \\
\text { Beam splitter material CaF2. } \\
\text { Recommended fiber (CIR) fibers. }\end{array}$ \\
& $\begin{array}{c}\text { Spectral range (1-6 } \mu \text { m) i.e. (5000-1700cm-1). } \\
\text { Gives the output spectrum of the sample. } \\
\text { Detector response for a selective wavelength } \\
\text { band. }\end{array}$ \\
\hline \hline
\end{tabular}

The employed ignition composition was ( $\mathrm{KClO} 3, \mathrm{Mg}$, and Carbon black).

\subsection{Spectral measurements of decoy flares:}

Experimental setup for spectral performance measurements consists mainly of combustion chamber, optical fibers, spectrophotometer, data receiving and recording system (Figure 6). The distance between the specimen holder and optical fiber of the spectrometer was $1.5 \mathrm{~m}$. 


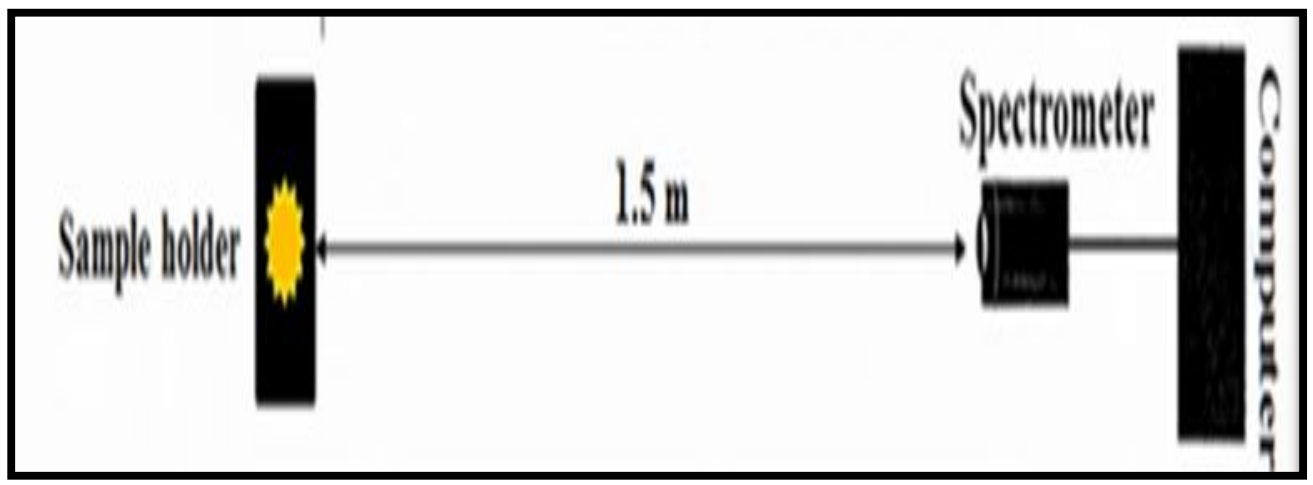

Fig. 6. Schematic for spectra measurements of developed decoy flares

The spectrometer response was (counts/s). After acquiring the spectral data, the average Intensity was conducted to retrieve the intensity (counts/s) over the $\alpha$ band (2-3) $\mu \mathrm{m}$ and $\beta$ and (3-5) $\mu \mathrm{m}$ and calculating theta as average intensity in $\alpha$ band over average intensity in $\beta$ band as follow $\boldsymbol{\theta}=\mathbf{I}_{\boldsymbol{\alpha}} / \mathbf{I}_{\boldsymbol{\beta}}$.

\section{Results and Discussion:}

\subsection{Effect of Magnesium Content on MTV Spectra}

These was an increase in the intensity of $\alpha$ and $\beta$ bands with the increae in $\mathrm{Mg}$ content. Figure 7 demonstrates the infrared spectra of the MTV formulations within the band 1-6 $4 \mathrm{~m}$ as function with $\mathrm{Mg}$ content.

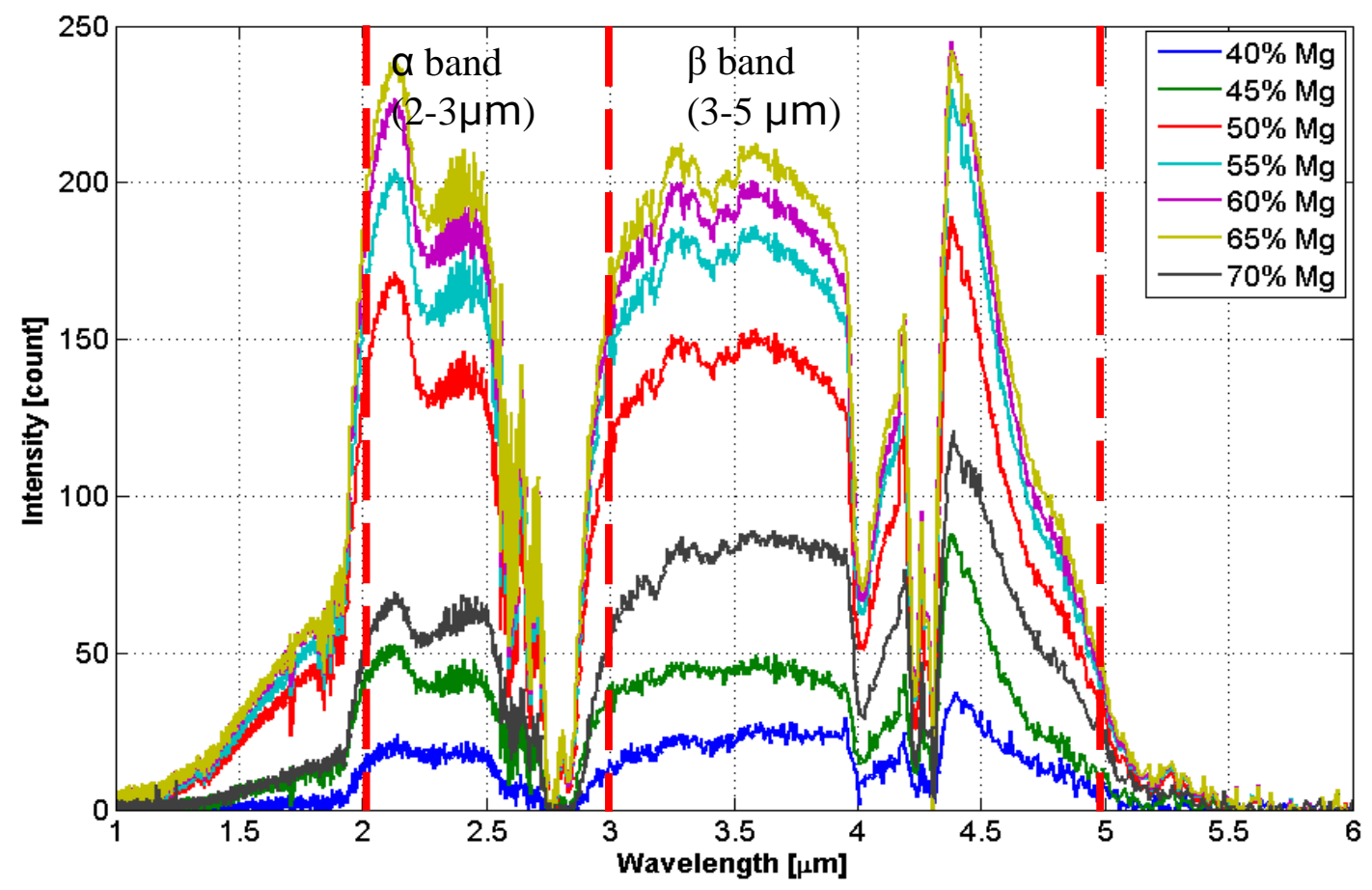

Fig. 7. Imprint spectra of MTV flare formulations with different magnesium fuel percentage

MTV formulation with $65 \mathrm{wt} \%$ magnesium offered the highest average intensity in the two bands $\alpha \& \beta$. The average intensity of $\alpha$ and $\beta$ bands was increased by 21 and 4 times respectively. The relative intensity ratio $\Theta$ was found to be 0.96 . This superior spectral performance was correlated to the optimized combustion process, which could lead to 
maximum formation of main infrared emitting species. This customized formulation offered the highest percentage (42.2 wt \%) of condensed $\mathrm{MgF}_{2}$ (main IR emitting species), 48 wt \% $\mathrm{Mg}$ (metal fuel), and $8.8 \mathrm{wt} \%$ carbon soot. Table 4 demonstrates the quantification of combustion products as well as combustion temperature using ICT thermodynamic code.

Table 4. The impact of fuel percentage on the formation of reactive emitting species

\begin{tabular}{c||c|c|c|c|c|}
\hline \hline Fuel \% & $\begin{array}{c}\mathrm{C}(\mathrm{s}) \\
\mathrm{Wt} \%\end{array}$ & $\begin{array}{c}\mathrm{Mg}(\mathrm{g}) \\
\mathrm{Wt} \%\end{array}$ & $\begin{array}{c}\mathrm{MgF}_{2}(\mathrm{~g}) \\
\mathrm{Wt} \%\end{array}$ & $\begin{array}{c}\mathrm{MgF}(\mathrm{g}) \\
\mathrm{Wt} \%\end{array}$ & $\begin{array}{c}\mathrm{MgF}_{2}(\mathrm{l}) \\
\mathrm{Wt} \%\end{array}$ \\
\hline \hline $40 \%$ & 14.81 & 7.219 & 58.9 & 17.3 & 0 \\
\hline $45 \%$ & 13.61 & 14.6 & 52.9 & 15.5 & 2.3 \\
\hline $50 \%$ & 12.4 & 22.21 & 34.3 & 14.2 & 16.06 \\
\hline $55 \%$ & 11.209 & 30.4 & 18.44 & 10.96 & 28.5 \\
\hline $60 \%$ & 10.01 & 39.19 & 5.92 & 5.7 & 38.8 \\
\hline $65 \%$ & 8.811 & 48.108 & 0.097 & 0.402 & 42.4 \\
\hline $70 \%$ & 7.6 & 55.5 & 0.00 & 0.00 & 36.5 \\
\hline \hline
\end{tabular}

$\mathrm{MgF}_{2}$ is a molecular species that would emit in the infrared region. This active species could be formed in the primary flame zone (1) next to the burning surface (Figure 8). This primary zone is characterized with high combustion temperature and high density of carbonaceous particles heated up by primary combustion products (i.e. $\mathrm{MgF}_{2}$ ). This carbonaceous particles (carbon soot) at high temperature could be an ideal emitter (grey emitter with $\varepsilon=0.9$ ).

Adjacent to the primary reaction zone is a secondary zone (2) where excess Mg fuel would vaporize and combusted with surplus air oxygen to $\mathrm{MgO}$ (grey emitter) adding substantial heat. The outer zone (3) demonstrates thermally excited glowing carbonaceous particles that undergo combustion to form $\mathrm{CO}_{2}$. Morover,carbon oxidized by oxygen and yeild strong peak emission at $2 \mu \mathrm{m}$ and strong emission bands at $4.3 \mu \mathrm{m}$. At this zone (3) complete oxidation of combustion, products could take place. Figure 8 demonstrate the combustion model for typical MTV flares.

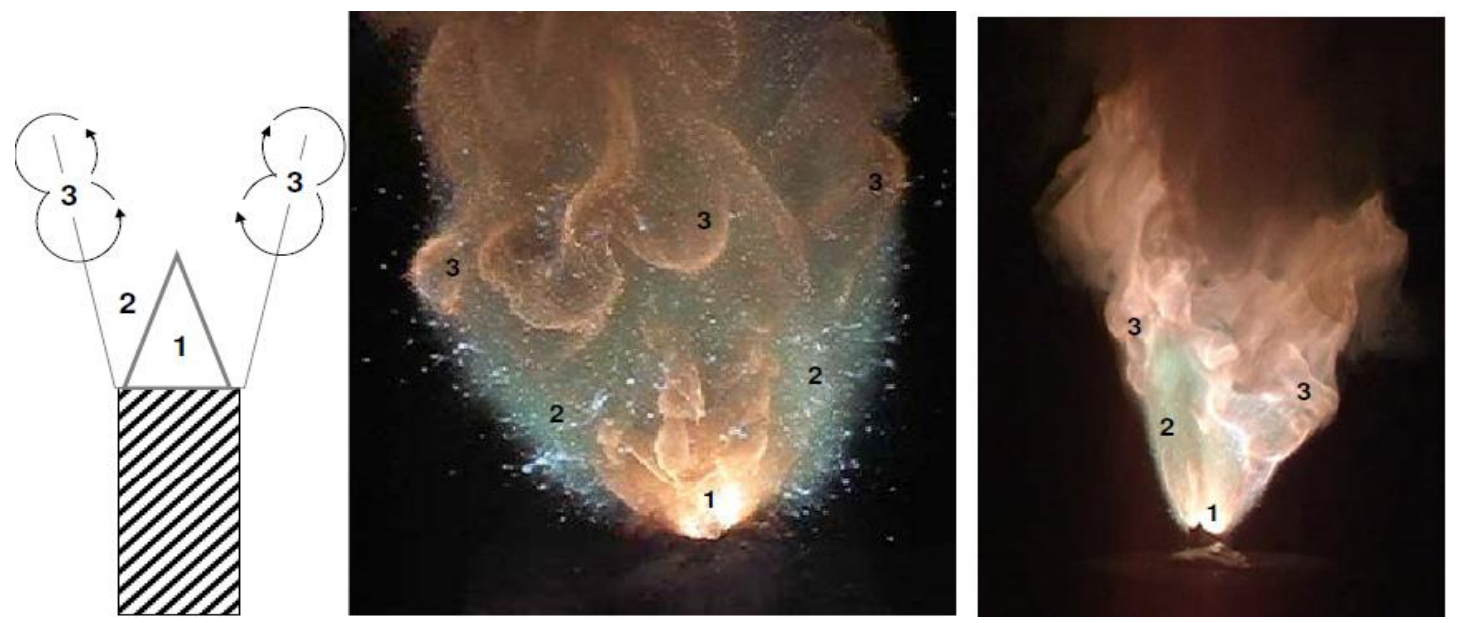

Fig. 8. Model for MTV flare combustion (a) with real photo-image for MTV flame (b, c)

\subsection{Thermal signature of MTV flares to jet engine nozzle:}

Comparative investigation between thermal signature of jet engine nozzle and customized MTV flare with highest spectral performance was conducted. The thermal signature of jet engine was characterized with two characteristic peaks over $\alpha$ and $\beta$ bands. Jet engine thermal signature was correlated to black body emission by the hot nozzle at $690{ }^{\circ} \mathrm{C}$. Absorption of the IR emission by air $\left(\mathrm{CO}_{2}\right.$ and $\left.\mathrm{H}_{2} \mathrm{O}\right)$ could attenuate the signal over the band 3-4 $\mu \mathrm{m}$. Average intensity ratio $(\Theta)$ of the jet engine $=0.3$. The MTV decoy flare offered similar $\alpha$ and $\beta$ bands but with higher intensity due to the formation of active IR emitting species in the combustion 
flame[29]. Customized MTV decoy flare with $65 \mathrm{wt} \% \mathrm{Mg}$ offered an increase in the intensity of $\alpha$ and $\beta$ bands by 21 and 4 times respectively. This customized formulation offered $\Theta$ value of 0.96. Figure 9 demonstrates the thermal signature of jet engine to customized MTV flare with $65 \mathrm{wt} \%$ fuel.

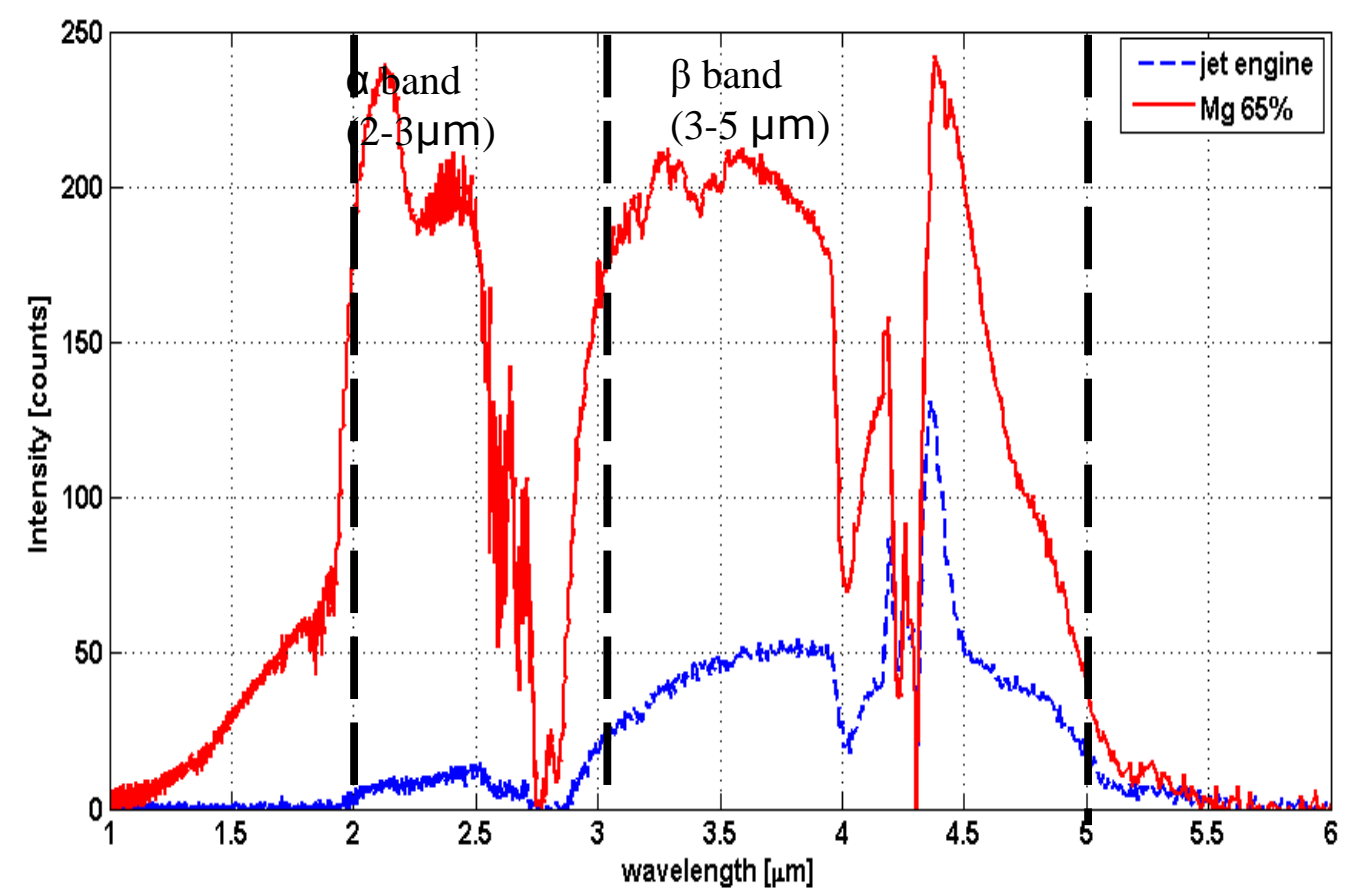

Fig. 9. Imprint spectrum of customized MTV flare to thermal signature of $\mathrm{j}$ engine nozzle

\subsection{Effect of magnesium content on $\alpha$ and $\beta$ bands average intensity :}

The variation of average intensity of $\alpha$ and $\beta$ bands with magnesium content was evaluated using (mat lab software) Figure 9 demonstrate the impact of magnesium content on $\alpha$ and $\beta$ bands average intensity.

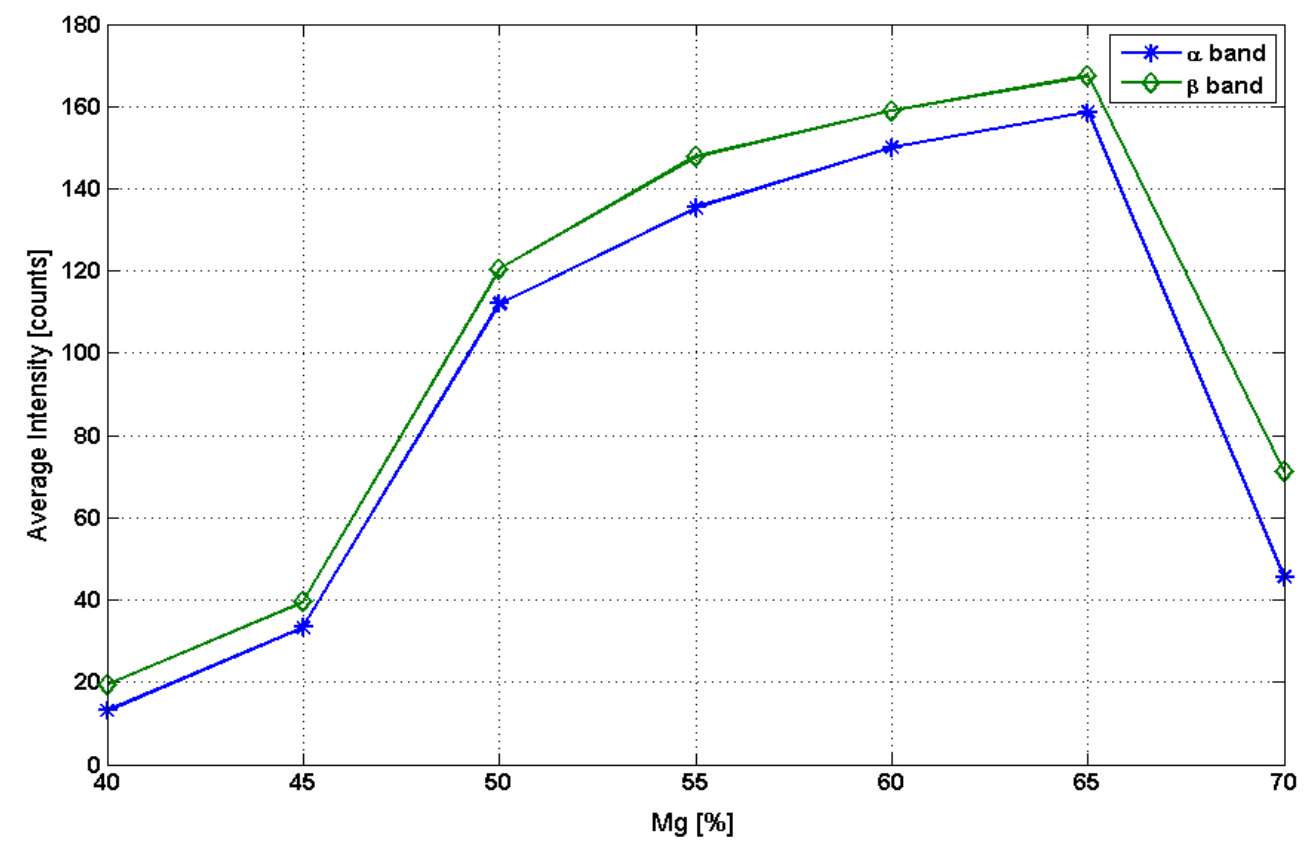

Fig. 10. Average intensity characteristics as function of (Mg) percentage 
The effect of magnesium content can be categorized into three main regions:

* There was a dramatic increase in $\alpha$ and $\beta$ bands with Mg content (40: $50 \mathrm{wt} \%$ )

* There was a slight increase in $\alpha$ and $\beta$ bands with Mg content (50: $65 \mathrm{wt} \%$ )

* There was a decrease in average intensity of with Mg content (higher than 65 wt \%).

\section{Conclusion}

MTV flares should have a fuel rich system for enhanced ignitability and combustion stability. The major reaction products are $\mathrm{MgF}_{2}$ (condensed), $\mathrm{MgO}(\mathrm{s})$, and carbon dioxide. MTV decoy flare with $65 \mathrm{wt} \% \mathrm{Mg}$ offered an increase in the intensity of $\alpha$ and $\beta$ bands to that of real jet engine nozzle by 21 and 4 times respectively. This superior spectral performance was correlated to the high content of combustion gasses with the main infrared emitters including MgF2 ( molecular infrared emitter with $42.4 \mathrm{wt} \%$ ), carbon soot ( grey infrered emitter with $\varepsilon=0.9$ ). The excess magnesium metal fuel could vaporize and burin with air oxygen adding substantial heat and excite the carbon soot and forming $\mathrm{MgO}$ (grey emitter $\varepsilon=0.4$ ). The oxidation of carbon soot to $\mathrm{CO}_{2}$ would yeild strong peak emission at $2 \mu \mathrm{m}$ and strong emission bands at $4.3 \mu \mathrm{m}$. This paper shaded the light on the real development of customized MTV flares with tailored spectral performance as an effective countermeasure of infrared seekers.

\section{References}

[1] E.-C. Koch, Review on Pyrotechnic Aerial Infrared Decoys, Propellants, Explos., Pyrotech. 2001, 26, 3.

[2] H. Radies, PhD thesis, Ludwig-Maximilians-University Munich, 2009.

[3] S. P. Mahulikar, H. R. Sonawane, Progress in Aerospace Sciences 2007, 43, 218.

[4] J. S. Acetta, D. L. Shumaker, The Infrared and Electro-Optical Systems Handbook, Vol. 5, Passive Electro-Optical Systems, SPIE Optical Engineering Press, Bellingham, 1996, 220.

[5] http://3.bp.blogspot.com/_J4nYRGAodHs/TQIkpMVGZSI/AAAAAAAAAgs/6HS8p2 Q_ldI/s1600/us_kampfjet.jpg [Stand: 2.11.2012].

[6] E. C. Koch, Pyrotechnic Countermeasures II, Propellants, Explosives, Pyrotechnics 2006, 31,3 .

[7] JOHN A. CONKLING CHRISTOPHER J. MOCELLA chemistry of pyrotechnics basic principle and theory second edition 2010.

[8] M. D. Earle "Infrared Countermeasures Techniques" in J. A.Boyd, D. B. Harris, D. D. King, H. W. Welch (eds.), "Electronic Countermeasures", Peninsula Publishing, Los Altos Hills, CA,1978, p. 22.2.

[9] J. H. McLain, “Pyrotechnics", The Franklin Institute Press, PA,1980, p. 91.

[10] G. T. Hahn, P. G. Rivette, and R. G. Weldon, U.S. Patent 5679921 (1997), The United States of America as represented by the Secretary of the Navy, USA.

[11] N. Brune "Expendable decoys" in J. S. Acetta, D. L. Shumaker,"'The Infrared and Electro-Optical Systems Handbook", Vol. 7, SPIE Optical Engineering Press, Bellingham, WA, 1996, p. 299.

[12] J. S. Acetta, D. L. Shumaker, The Infrared and Electro-Optical Systems Handbook, Vol. 5, Passive Electro-Optical Systems, SPIE Optical Engineering Press, Bellingham, 1996, 220.

[13] G. T. Hahn, P. G. Rivette and R. G. Weldon, U.S. Patent 5679 921, the United States of America as represented by the Secretary of Navy, USA, (1997). 
[14] G. T. Hahn, P. G. Rivette and R. G. Weldon, U.S. Patent 5679 921, The United States of America as represented by the Secretary of Navy, USA, (1997).

[15] M. D. Earle, "Infrared Countermeasure Techniques", in: J. A. Boyd, D. B. Harris, D. D. King and H. W. Welch (eds.), " Electronic Countermeasures", Peninsula Publishing, Los Altos Hill, p. 22 (1978).

[16] H. Ellern, " Military and Civilian Pyrotechnics", Chemical Publishing Company,New York, P. 412, (1968).

[17] V. Bhingarkar, H. Gandhi, P. Phawade, and H. Singh, 'Sensitivity and Thermal Analysis of MTV Igniter Compositions" Proc. of the 30th Int. Ann. Conference of ICT, Karlsruhe, 29 June \pm 2 July 1999, ICT Karlsruhe 1999.

[18] A. Peretz, "Investigation of Pyrotechnic MTV Compostions for Rocket Motor Igniters", Proc. of the 18th Joint Propulsion Conference, 1982 Cleveland Ohio, AIAA-82-1189.

[19] T. Kuwahara and T. Ochiai, "Burning rate of Mg=Tf pyrolants", Proc. of the 18th International Pyrotechnics Seminar, 1992.

[20] J. P. Rosada and P. Rousseau, French Patent FR 93 09341, Etienne Lacroix-Tous Artifices, France, (1993).

[21] P. G. Pelham and D. W. Smith, UK Patent GB 2283303 B, The Secretary ofState for Defence, United Kingdom (1995).

[22] A. Raz, UK Patent GB2327A Israel Military Industries Ltd, Israel, (1997).

[23] R. Tappan, R. C. Anderson and D. W. Endicott Jr., WO Patent 96/34249, Thiokol Corporation, USA, (1996).

[24] D. B Nielson and D. M. lester, US Patent 5470 408, Thiokol Corporation USA,(1995).

[25] T. Kuwahara and T. Ochiachi, " Burning Rate of Mg/Tf Pyrolants", $18^{\text {th }}$ International Pyrotechnics Seminar, P 359 - 549, (1992).

[26] N. Davies , "Pyrotechnic counter measure to IR seeking missile" 18-20th march1998, Royal United Service Institute, London, (1998)

[27] T. Jone, UK Patent GB 2266944 B, GEC-Marconi Limited, United Kingdom, (1995).

[28] P. Atkins, Physikalische Chemie, Wiley-VCH, 2001.

[29] Ernst-Christian Koch* and Axel Dochnahl" IR Emission Behaviour of Magnesium/Teflon/Viton (MTV) Compositions"Propellants, Explosives, Pyrotechnics 25, 37-40 (2000).

[30] kyung JooYi1,Seung Wook Baek1,Bonchan Gu1, Sung Nam Lee2, Man Young Kim3, and Won Cheol kim4 "INFRARED SIGNATURE STUDY OF AIRCRAFT EXHAUST PLUME" February 24 - 28, 2014, Honolulu, HI, USA.

[31] Ernst-Christian Koch* Diehl BGT Defence GmbH \& Co. KG, F ischbachstrasse 16, D90552 Rçthenbach a. d. Pegnitz, Germany" Pyrotechnic Countermeasures: II. Advanced Aerial Infrared Countermeasures", Propellants, Explosives, Pyrotechnics 31, No. 1 (2006). 